2 Corresponding Author: Wei Yan, Ph.D. Telephone: 1979 8450584. Fax: 979-862-1571. Email:

wyan@tamu.edu 


\section{BPOpt: A Framework for BIM-based Performance Optimization}

\section{Abstract}

7 The increase in global environmental concerns as well as advancement of computational tools and

8 methods have had significant impacts on the way in which buildings are being designed. Building

9 professionals are increasingly expected to improve energy performance of their design. To achieve a high

10 level of energy performance, multidisciplinary simulation-based optimization can be utilized to help

11 designers in exploring more design alternatives and making informed decisions. Because of the high

12 complexity in setting up a building model for multi-objective design optimization, there is a great demand

13 of utilizing and integrating the advanced modeling and simulation technologies, including BIM,

14 parametric modeling, cloud-based simulation, and optimization algorithms, as well as a new user interface

15 that facilitates the setup of building parameters (decision variables) and performance fitness functions

16 (design objectives) for automatically generating, evaluating, and optimizing multiple design options. This

17 paper presents an integrated framework for Building Information Modeling (BIM)-based Performance

18 Optimization, BPOpt. This framework enables designers to explore design alternatives using an open-

19 source, visual programming user interface on the top of a widely-used BIM platform, to generate models

20 of building design options, assess the environmental performance of the models through cloud-based

21 simulation, and search for the most appropriate design alternatives. This paper details the process of the

22 development of BPOpt and also provides a case study to show its application. The case study

23 demonstrates the use of BPOpt in minimizing the energy consumption while maximizing the appropriate

24 daylighting level for a residential building. Finally, strengths, limitations, current adoption by academia

25 and industry, and future improvements of BPOpt for high-performance building design are discussed.

26 Keywords: Building Information Modeling; BIM, Performance-based Design; Building Performance

27 Optimization; Multi-Objective Optimization; Parametric Modeling; Visual Programming.

\section{Introduction}

The building sector is the largest consumer of the United States primary energy and accounted for $40 \%$ of carbon dioxide emission in the country in 2010 (US Dept. of Energy, 2012). Meanwhile, the building sector has the greatest potential for carbon reduction with the lowest cost (Sustainable Buildings and 
Climate Initiative, 2009). Due to the considerable impact of the buildings on the environment and with the increase in environmental concerns, building professionals are increasingly expected to improve energy performance of their design. Applying individual sustainable strategies would help improving the performance of the building to some extent. However, achieving high level energy performance requires application of the optimal combination of several strategies (Stevanović, 2013). In the meantime, improving building performance by applying separate strategies can be simple, but optimizing the design performance is a difficult task because of its high complexity (Wang et al., 2005; Wright et al., 2002).

Multidisciplinary optimization for high performance building design is a method with potentials to: 1) provide desired performance feedback for decision making during the design process; 2) help designers with creative design space exploration and provide an expanded set of design alternatives and the assessment of their impacts on the performance; and 3) support designers in decision making by ranking design alternatives according to multiple design criteria (Lin and Gerber, 2014a). Although optimization is undoubtedly a promising method to achieve high performance building design, due to its inherit complexity, it is not commonly used in the design practice yet and currently its use is mainly limited to a few academic research studies. The complexity comes from the large number of multi-disciplinary interrelated parameters involved in optimizing building performance as well as the complex natures of building simulation outputs (Nguyen et al., 2014). Because of the high complexity in setting up a building model for multi-objective design optimization, there is a great demand of utilizing and integrating the advanced modeling and simulation technologies, including BIM, parametric modeling, cloud-based simulation, and optimization algorithms, as well as a new user interface that facilitates the setup of building parameters (decision variables) and performance fitness functions (design objectives) for automatically generating, evaluating, and optimizing multiple design options.

A systematic integration of parametric Building Information Modeling (BIM) and building performance analysis can provide a new workflow that will make the building performance optimization more accessible for innovative energy-efficient building design. BIM delivers relevant building information required for building energy performance analysis and if used appropriately can save a significant amount of time and effort in preparing input data for building performance simulation while reducing errors (Kumar, 2008). Though parametric BIM-based performance optimization could significantly benefit high performance building design, there are only a very limited number of research studies on creating an integrated methodological framework for BIM-based multidisciplinary performance optimization. Welle (2012) developed ThermalOpt, a multidisciplinary design optimization (MDO) workflow for automated BIM-based thermal simulation. ThermalOpt was the first reported research study to mitigate technical barriers to BIM-based multidisciplinary performance optimization while integrating commercially 
available technologies into a workflow. Welle at al. (2011) reported there are seven modeling requirements for ThermalOpt that the designer needs to follow (most of them are due to the limitations of

67 the BIM tool, Digital Project) to conduct a successful optimization. In addition, ThermalOpt uses ModelCenter ${ }^{\circledR}$ (Phoenix Integration, 2013) as the MDO environment which requires extensive training to define the trade study strategy. More recently, Lin (2014) developed an Evolutionary Energy Performance Feedback for Design (EEPFD) framework that enables complex geometric form exploration via energy performance feedback in the early design stage using a BIM tool. The EEPFD uses Microsoft ${ }^{\circledR}$

72 Excel for storing financial parameters and formulas, and also a user interface proxy in which designers 73 can set up design parameters. EEPFD is designed for the parametric conceptual models in Autodesk ${ }^{\circledR}$

74 Revit mass family and as a result does not fully utilize the detailed analytical properties of building 75 objects (i.e. thermal properties) in BIM for performance analysis.

Both of the abovementioned research studies introduce a successful methodological framework to

77 mitigate the technical barriers of the BIM-based thermal simulation and design optimization and make them more accessible in the process of design. In this paper, we introduce a BIM-based Performance Optimization (BPOpt) framework that tries to overcome the limitations of the previous research studies and provides an integrated, easy-to-setup, and expandable multidisciplinary performance optimization 81 tool on the top of widely-used BIM platform, Autodesk ${ }^{\circledR}$ Revit. BPOpt uses a visual programming user

82 interface for users to setup building parameters and performance fitness functions, utilizing the significant 83 benefits of visual programming (Myers, 1990), especially in architecture (Boeykens and Neuckermans, 84 2009).

BPOpt integrates visual programming-based parametric BIM with building thermal and daylighting simulations (as sample design objectives) to optimize building design. As a part of BPOpt, Optimo was

87 developed by the authors as an open-source, visual programming-based Multi-Objective Optimization 88 (MOO) tool for BIM (which has been downloaded more than 500 times by public users as of May 2015) 89 to explore the design space and provide a set of optimal solutions to the designers. In this paper we 90 demonstrate the functionality of BPOpt in a case study by optimizing the energy and daylighting 91 performance of a residential building design. However, the applicability of BPOpt framework is not 92 limited to these two performance metrics and can be expanded to include other building performance 93 metrics as described in the coming sections. 


\section{Background}

95 Most of the fundamental work on building performance simulation algorithms was developed a few

96 decades ago. Nevertheless, building simulation tools became widely available to designers during the past

97 few years with the advancement of computational tools and methods. The increase in global

98 environmental concerns accompanied with the availability of building performance simulation tools has

99 had a significant impact on the way in which buildings are designed (Malkawi, 2004). As a result of this

100 change, designers are expected to consider energy performance by exploring design alternatives that are

101 more promising to save energy in the earlier phases of project. However, exploring design alternatives

102 parametrically and optimizing the performance at the early design stage is still a challenge for design

103 professionals due to the lack of appropriate tools (Lin and Gerber, 2014a). In recent years, an increasing

104 amount of literature on optimizing building performance has been published (De Boeck et al., 2013) but

105 BIM-based building performance optimization has only a few research studies (Flager et al., 2012; Lin and Gerber, 2014a; Welle et al., 2011).

In multiple phases of a building project, the designer needs to interact with various design and simulation tools and to predict the performance of the model, which makes the interoperability among different software tools a necessity. A large and growing body of literature has reported that the seamless integration between these software programs is typically lacking (Attia et al., 2012a; Lin and Gerber, 2014b; Welle et al., 2011; Yan et al., 2013). Augenbroe (2002) reported two major movements started in parallel with similar goals in mind to address this issue: 1) a collective effort by industry, governmental and research organizations to establish data exchange standards for the building industry such as Industry Foundation Classes (IFC) (Bazjanac and Crawley, 1999) or Green Building eXtended Markup Language (gbXML) (gbXML, 2014); and 2) researchers and the industry attempt to address the existing interoperability issues across different software platforms by scripting interfaces and self-developed applications between the design and performance analysis domains (Attia et al., 2012a; Lin and Gerber, 2014a; Welle et al., 2011). Whereas the former tries to remove inefficiencies in data sharing by representing the relevant data within each program to a generic common data model that contains the required information by all other programs, the latter is aiming to functionally create a connection among two or more design and performance simulation software tools for specific goals.

To address the significant need for parametric design tools integrated with building performance analysis and to improve the building design process, various studies have been done (Jakubiec and Reinhart, 2011; Lagios et al., 2010; Niemasz et al., 2011; Paoletti et al., 2011; Roudsari and Pak, 2013; Sargent et al., 2011; Shi and Yang, 2013). These studies try to enable designers to explore various design options and 
access energy performance analysis results quickly. The common goal of all of these studies is to create a toolkit to make the parametric performance-based building design more accessible in the early design phase. Most of these tools are created on top of Rhinoceros ${ }^{\circledR}$ (Rhino), a 3D NURBS modeling program, because of its tightly integrated visual programming editor, Grasshopper ${ }^{\circledR}$, which facilitates parametric design (McNeel, 2015). These studies try to create workflows to integrate Rhino/Grasshopper with building performance analysis tools. For instance, Lagios et al. (2010) created a workflow within Rhino/Grasshopper to export scenes (geometry, material properties, and sensor grids) to Radiance/ DAYSIM to calculate a series of daylighting performance indicators. Jakubiec and Reinhart (2011) described a design workflow for integrating daylighting analysis using Radiance/DAYSIM and thermal analysis using EnergyPlus within their plugin called DIVA. Roudsari and Pak (2013) developed a free and open source plugin that connects Grasshopper to EnergyPlus, Radiance, DAYSIM and OpenStudio for building energy and daylighting analysis. They also created Ladybug to import EnergyPlus weather files (.EPW) for better understanding of the weather data and to visualize the building performance analysis results (Roudsari et al., 2013). Some studies added existing optimization tools to the process of parametric building energy simulation to help designers in finding an optimal set of solutions for a specific project. For instance, Shi and Yang (2013) created a performance driven workflow by integrating Ecotect with Rhino/Grasshopper to obtain an optimal roof shape using a single objective optimization algorithm. Aly and Nassar (2013) used DIVA along with Galapagos, an Evolutionary Algorithm plugin in Grasshopper, to optimize urban daylight performance. Bechthold et al. (2011) used DIVA to integrate environmental design and robotic fabrication for shading systems. Although these studies created parametric architectural design workflows with performance optimization available in Rhino/Grasshopper, they do not have access to actual building assemblies and properties available in BIM.

BIM represents the building as an integrated database of coordinated information and enables information sharing for interoperability between prevalent software tools. BIM can be used as the central model for the analysis of the multiple performance criteria including architectural, structural, energy, acoustical, lighting, etc. (Ahn et al., 2014; Fischer, 2006). BIM-based high performance building design is increasingly being used in the architectural design disciplines and allows practitioners efficiently generate and modify building models (Welle et al., 2011). The existing studies that consider BIM as the central data model for building energy performance analysis are mainly focused on automatic preparation of the building energy model for various energy simulation tools such as DOE-2 (Maile et al., 2007), EnergyPlus (Bazjanac, 2008; Cormier et al., 2011; Maile et al., 2007), TRNSYS (Cormier et al., 2011), Ecotect and Green Building Studio (Azhar et al., 2009, 2011), and Modelica-based tools (Kim et al., 
2015; Yan et al., 2013). The common approaches in this type of research is to translate the BIM models to energy input files for solving interoperability issues with or without the use of IFC and to create an automatic link between BIM authoring tools and the building energy simulation engines.

Optimization studies are recently being used in building design after long being computationally intractable on multi-scale systems in various topics particularly building environmental performance. As a result, simulation-based optimization can be changed to an efficient process to satisfy several requirements of energy efficient buildings (Nguyen et al., 2014). During the past years, computational optimization methods applied to building performance analysis have become very popular in academia and have been applied to a wide range of problems such as building form, envelope design, configuration and control of HVAC, and renewable energy generation (Evins, 2013; Malkawi, 2005). There are a few comprehensive reviews published on research studies applying computational optimization to building performance analysis. Evins (2013) published an inclusive review of 74 significant research studies applying computational optimization to different fields of sustainable building design and speculated about future trends and challenges. Stevanović (2013) gave a thorough review of the research studies of simulation-based optimization of passive solar design strategies. Nguyen et al. (2014) provided an overview on the advances, outlining potential challenges and obstacles in building energy performance optimization. Machairas et al. (2014) reviewed performance-based design optimization methods and tools and studied their abilities and performance issues, as well as the reasoning behind their selection.

Moreover, they identified the key characteristics of the future versions of design optimization methods.

Simulation-based optimization for energy efficient building design can be very complicated and time intensive since each design alternative evaluation requires input from multiple disciplines as well as multiple simulation runs. In the literature, there are four common approaches to address this issue: 1) to use surrogate models that are built to approximate computationally expensive simulation codes (Ong et al., 2003; Wetter and Polak, 2004); 2) to develop computational algorithms that reduce the number of runs (Coley and Schukat, 2002; Wetter and Wright, 2004); 3) to develop computational algorithms for model decomposition and recomposition to reduce the size of runs (Welle et al., 2012); and 4) to increase the computational power through multi-threading, parallelization, and cloud-based simulation (Garg et al., 2010; Rahmani Asl et al., 2014; Zhang and Korolija, 2010).

In the process of design optimization there are many physical processes that lead to multiple conflicting objectives. For many multi-objective optimization problems, it is not always possible to find one optimal design solution that optimizes all design objectives. In traditional optimization techniques a composite objective function is defined by combining all of the individual objective functions. The composite 
objective function can be determined with various methods, like the use of weighting factors.

192 Determining the composite objective function needs knowledge of the relationships among individual

193 objectives and their weighting factors (Konak et al., 2006). Nevertheless, in building design these

194 relationships are unknown in many cases. Moreover, due to the difficulty of including factors such as

195 aesthetics in the optimization process, it is likely that any optimum result will be found to be unacceptable

196 (Coley and Schukat, 2002). Another approach is to set multiple objectives and use the concept of Pareto

197 optimality, which is a set of promising solutions, known as Pareto-optimal set (Fonseca and Fleming,

198 1993), given multiple objectives. Pareto Optimality supports decision making by finding the equally

199 optimal solutions such that it is not possible to improve a single individual objective without causing at

200 least one other individual objective to become worse off (Hoes et al., 2011). Selecting the best solution

201 from the Pareto set is not a trivial problem as it depends on a number of aspects (Nguyen et al., 2014). A

202 posteriori set of preferences may be used to evaluate the optimal solutions and find the unique solution by

203 the designers (Gossard et al., 2013).

204 BPOpt presented in this paper is built upon the authors' previous work (Rahmani Asl et al., 2014, 2013)

205 that introduced BIM-based parametric building simulation and optimization, with a significant extension

206 to include the detailed introduction of the entire optimization framework and its components: an easy-to-

207 setup, open-source visual programming optimization engine - Optimo, which can be used by public users

208 in their own projects, and major cloud-based energy and daylighting simulation tools, as examples to

209 demonstrate how to use BPOpt in the projects. Moreover, the presented BPOpt framework in this paper is

210 improved to address parametric changes of thermal properties of building construction materials for

211 energy and daylighting simulation, which is described in detail in the following sections. The next section

212 provides an overview of BPOpt and the overall structure of Optimo, and parametric energy and

213 daylighting simulation tools. Section 4 presents the results of the applying BPOpt on residential building

214 as a case study followed by discussion and conclusion.

\section{3. Methodology}

216 In response to the observed gaps in the literature, BPOpt is developed as an integrated framework to 217 establish multidisciplinary optimization in the process of performance-based design. Figure-1 shows the

218 overview of BPOpt and the overall optimization and performance simulation tools that were developed

219 and used in this research. The BPOpt framework is developed on the top of a widely used BIM tool,

220 Autodesk Revit ${ }^{\circledR}$, and its visual programming tool, Dynamo (2015), to integrate the rich information

221 stored in parametric BIM with building performance simulation tools and make performance optimization 
more accessible in the process of design. Dynamo is an open-source visual programming application that

223 interacts with Revit to extend its parametric capabilities to the Revit project level. It also provides an

224 environment to create customized packages using scripting and sharing it with other users. BPOpt

225 containing Optimo, energy simulation, and daylighting simulation packages is created by utilizing Revit

226 Application Programming Interface (API) and Dynamo. BPOpt is compatible to user defined building

227 performance simulation packages (energy and daylighting simulation packages for the case study of this

228 research paper). Other simulation packages can be easily added into the BPOpt framework, i.e. structural analysis package is created and used following the BPOpt framework by an industry user to optimize structural performance of the building (Vermeulen, 2015). The following sub-sections describe the details of Optimo, energy analysis, and daylighting analysis.

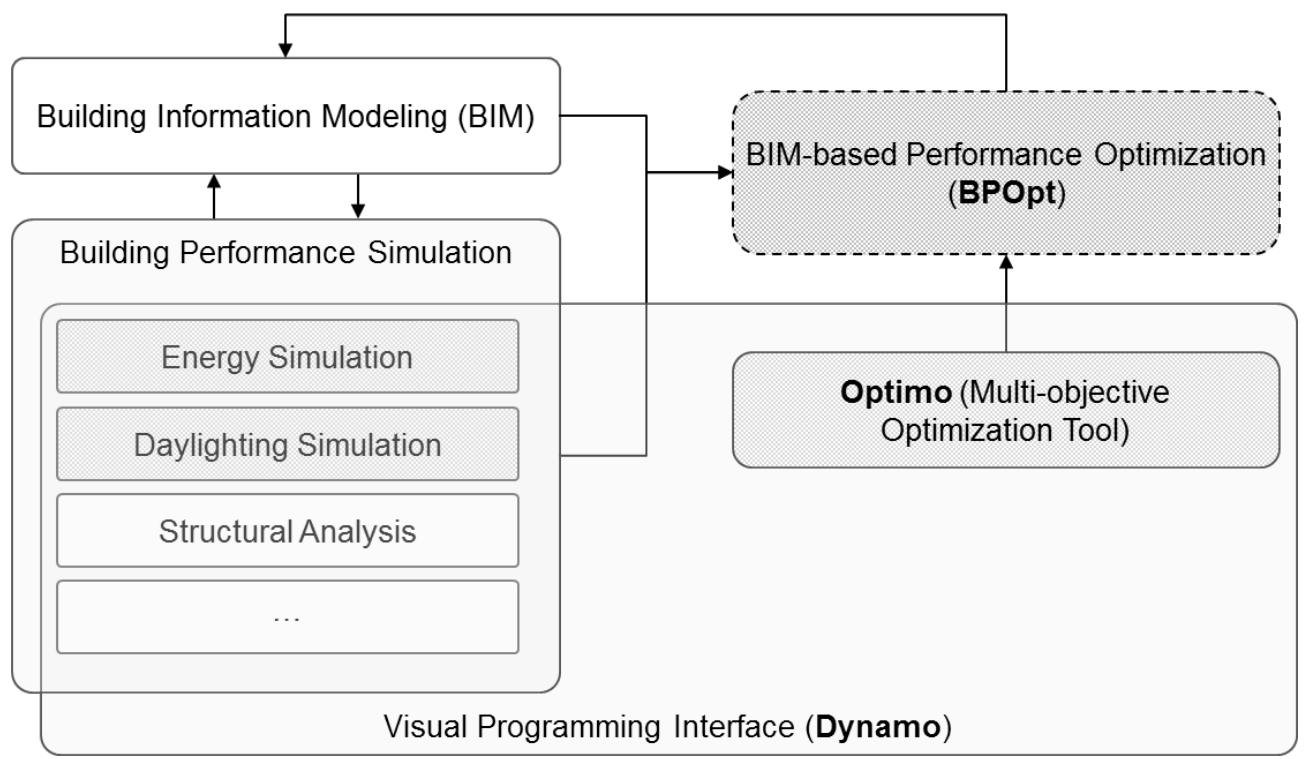

Figure-1. The overview of BPOpt framework

\subsection{Optimo}

As a part of the BPOpt workflow, Optimo, an open-source MOO package, is developed to parametrically interact with Autodesk Revit for BIM-based optimization (project URL at Rahmani Asl et al., 2015). It is developed as an application that can be installed as a package for Dynamo and works based on the Nondominated Sorting Genetic Algorithm-II (NSGA-II) (Deb et al., 2002). Optimo is developed based on jmetal.NET open source code with the goal of providing C\# implementation of the Metaheuristic Algorithms in Java (Durillo and Nebro, 2011). Optimo is published as an open-source package under GNU Lesser General Public License (2015) and is available to the public. The Optimo package is 

2015.

244 Figure-2 shows a schematic view of Optimo in Dynamo version 0.7.5. The user has an option to define the population size, the number of objectives, and the decision variable domains. In InitialSolutionList node a random parent population list of size $N$ is created which includes values for the decision variables. The user can define fitness functions as shown in the chart. The fitness function result values are added to the initial population list in AssignFitnessFuncResults node by joining the initial solution list of decision variables and fitness function results.

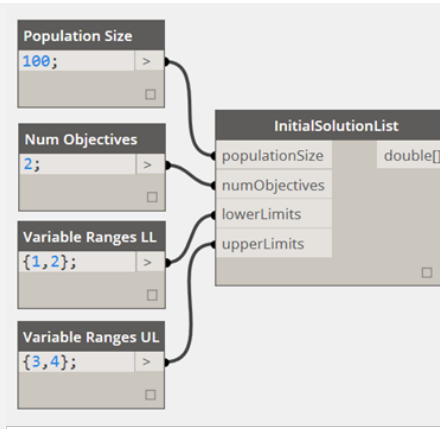

Figure-2. Schematic view of Optimo in Dynamo version 0.7.5

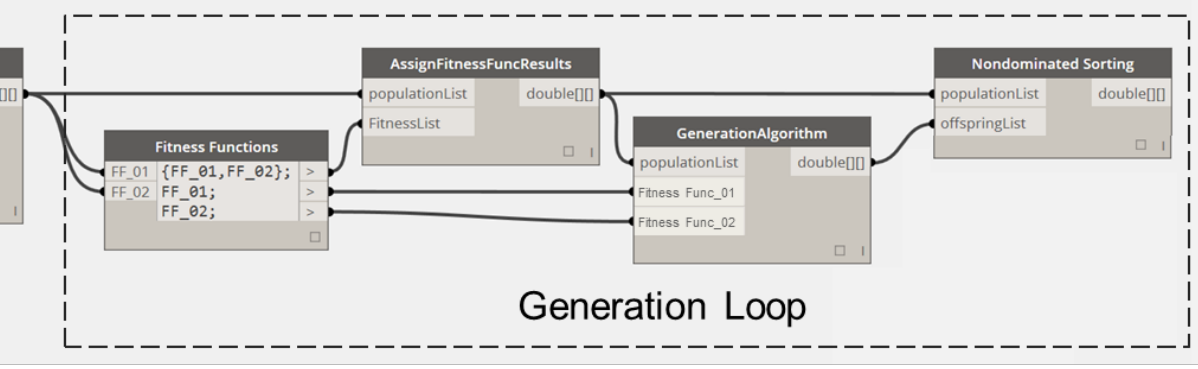

In the GenerationAlgorithm node, the initial population list is sorted using the assigned fitness values based on the non-domination sorting method and the usual binary tournament selection, crossover, and mutation operators are applied to create an offspring population list. The fitness values of the offspring population list are calculated and assigned in the same way as the initial population list and a combined population list with the size of $2 N$ is generated with the current offspring population list and previously found best nondominated solutions to ensure elitism. The combined population is sorted via the NondominatedSorting node. At this stage, the top $N$ solutions that belong to the best nondominated set are selected for the next iteration. The Generation Loop continues until the iteration counter reaches the limit set by the designer. The Pareto Optimal Set will be created as an output of the optimization loop and the complete set of initial solution list and the generated population lists during the optimization process are exported as a Comma Separated Values (CSV) file. The user can access the exported data for more detailed downstream process.

\subsection{Parametric Energy Simulation}

In response to the observed need for a parametric energy simulation tool, an automatic workflow is developed that enables designers to make parametric changes to the BIM model and simulate the energy performance accordingly. The parametric runs of the energy simulation enable designers to explore 
design alternatives and at the same time assess the building energy performance to search for the most energy efficient design. The designed workflow uses the project information, the geometry data, and the thermal properties of construction materials stored in the BIM model to create an analytical energy model.

271 This workflow generates energy model data in the gbXML open schema from BIM using Autodesk ${ }^{\circledR}$

272 Revit $^{(\mathbb{R})}$ s API. An automatic link is created between Revit and a web-based energy simulation engine -

273 Autodesk $^{\circledR}$ Green Building Studio ${ }^{\circledR}$ (GBS) as a part of the BPOpt framework by authors. GBS uses the

274 DOE-2.2 simulation engine. In 2008 Green Building Studio version 3.4 web service simulation results

275 were evaluated and the result met ANSI/ASHRAE Standard 140, Standard Method of Test for the

276 Evaluation of Building Energy Analysis Computer Programs, and certified by the U.S. Department of

277 Energy as a qualified computer software program for federal tax incentive requirements. The interaction

278 between Revit and GBS is enabled using Revit-API and GBS-API.

279 The generated gbXML file includes all of the energy analysis related information in the BIM model

280 defined by the user. Some of the required information for energy simulation in GBS such as project

281 location, building type, and building operating schedule are exposed in the Revit interface as Energy

282 Settings. These properties can also be modified through Revit API for parametric analysis. Additional

283 inputs that are necessary for the energy analysis are set as defaults based upon ASHRAE Standards by

284 GBS. The description of the defaults is provided in Autodesk GBS Help. The details of the input

285 assumption can be viewed in the GBS project as well.

286 The prior work of the present workflow could address parametric changes of building geometry within

287 Revit (Rahmani Asl et al., 20134). In the new complete workflow, the parametric changes of construction

288 thermal properties of building materials are addressed as well. The user can create various types of

289 building materials with different thermal performances and add them into a list for parametric study.

290 During the optimization process, the appropriate Revit Family's Type will be selected for energy

291 simulation. Hence, the updated workflow is able to parametrically change both form and thermal

292 properties of objects in the BIM model and assess the energy performance of the building model

293 accordingly.

294 The parametric energy simulation is designed in a way that it can explore the building performance and

295 overcome the barrier of the simulation being time consuming and explore the building performance using

296 cloud computing of GBS. In each generation of Genetic Algorithm optimization, the gbXML files for

297 design alternatives are uploaded to the GBS project and simulated in parallel on the cloud, which

298 minimizes the time for simulation runs. The simulation results are queried after all of the alternative runs 
are completed for that generation. This sub-process can be integrated into the optimization process as a part of the fitness function to optimize building energy performance.

\subsection{Parametric Daylighting Analysis}

Lighting Analysis for Revit is a cloud service that uses Autodesk Rendering Service to expose electric lighting and daylighting results directly on the BIM model. The daylighting simulation functions are accessible in Dynamo as a built-in functionality through a few nodes.

Using the Dynamo daylighting nodes and Python scripting, we have created a flexible daylighting simulation package for calculation of hourly illuminance values to enable automation of parametric daylighting analysis. This package uses Perez sky model and calculates the percentage of the area with illuminance level within the acceptable range set by LEED Version-4 Daylight Option-2. Based on LEED Version-4 Daylight Option-2 the building gets 1 point if the illuminance level of $75 \%$ of the regularly occupied area lies between 300 lux and 3,000 lux for 9 a.m. and 3 p.m., both on a clear-sky day at the equinox and it gets 2 points for more than $90 \%$ area within the illuminance range. The daylighting analysis can be integrated into performance optimization process as an objective function, which aims to maximize the occupied area of the building (or a part of the building) within the illuminance range between 300 lux and 3,000 lux. In other words, LEED daylighting requirements are used as a reference for creating one of the objective functions in the present study (the other being minimizing the annual energy cost described in the previous section.)

The developed package requires a user input for the building floor levels that the designer intends to include in daylighting simulation. The created daylighting package automatically finds the floors and the rooms assigned to the defined levels using Revit API via Python scripting in Dynamo. The floor is used to define the desk level and sensors needed for daylighting simulation and the room properties are used to check if the room is regularly occupied. Other necessary project information for daylighting analysis such as geometry and material properties are automatically collected from the BIM model and the daylighting simulation jobs are created also automatically in the cloud.

324 The developed package creates multiple daylighting analysis jobs and sends them for simulation to the 325 cloud in the same order that they are created in the package. After all of the daylighting analysis jobs are 326 submitted to the cloud simulation engine, the package starts collecting the results back from the cloud. 327 This process can reduce the simulation time using parallel simulation. (However, the current Autodesk 328 rendering and daylighting analysis server limits the number of parallel runs to 4 simultaneous runs for the 329 education accounts which limits the simulation time saving.) When all of the simulations are done, the 
daylighting results are collected from the server. The simulation results include a list of illuminance values for sensor points and the sensors position in the $3 \mathrm{D}$ environment. The developed Python script

332 parses the results and calculates the percentage of regularly occupied area with the illuminance level

333 within the LEED-acceptable range. This parametric daylighting analysis is integrated with parametric

334 energy simulation and Optimo to conduct building performance optimization.

\subsection{BPOpt workflow:}

The process of implementing BPOpt to optimize building performance and obtain feedback for design decisions can be described in the six major steps demonstrated in Figure-3 along with the tools that are used in each step. The first step is modifying the BIM model and implementing the necessary analytical properties for performance analysis. BPOpt is designed to automatically use the information stored in the BIM model such as building project properties, building geometry, and physical properties to create the analytical input file for performance simulation tools. The prototype created in the present research uses Autodesk $^{\circledR}$ Revit $^{\circledR}$ as the BIM tool and also as the central platform for the optimization process.

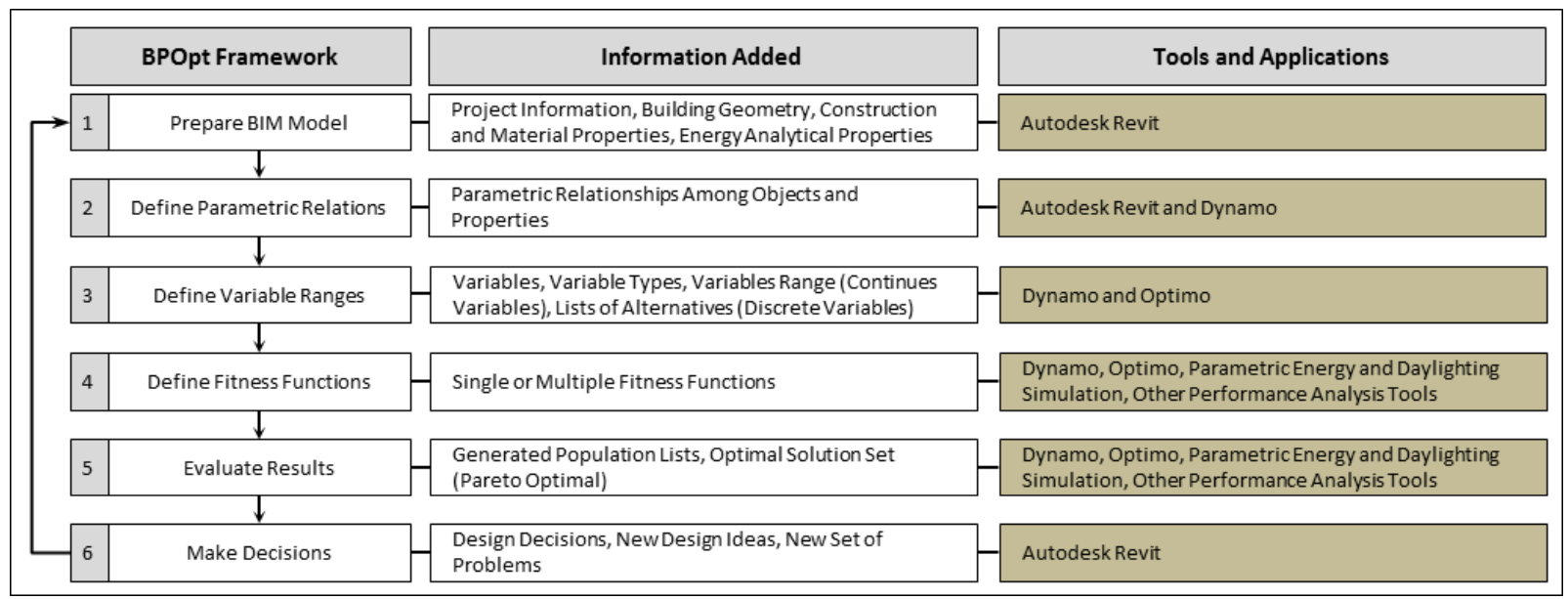

Figure-3. The process of implementing BPOpt to optimize building performance and the tools and applications that are used in the process

In the second step the parametric relationships among building objects should be defined. The parametric relationships can be defined either through the Revit interface, which is limited to parametric capabilities at the Family (building component) level, or with the use of Dynamo (2015) to extend its parametric capabilities to the project level. The parametric connections help propagation of parameter changes throughout the BIM model during the optimization process. The parametric BIM model changes in

351 response to the variable changes and then the corresponding analytical models, generated from the BIM model, get updated. 
In the third step, the designer defines the decision variables (independent variables) and their variation domain. Due to the large number of variables that the designer needs to consider in sustainable building

355 design, the number of possible combinations created by varying each variable in its practical range is 356 enormous (Coley and Schukat, 2002) and very difficult to manage. In response to this issue, BPOpt is 357 designed as an iterative process that provides the option for the user to re-define the variables and their 358 domain to approach the most appropriate design in a more manageable process. BPOpt can handle 359 multiple types of variables such as continuous numbers and discrete variables.

The user defines the fitness functions in the fourth step. The design process can have either a single fitness function (single objective optimization) or multiple fitness functions (multi-objective optimization). The fitness function can be defined as a simple function like project cost based on area and cost per unit or as a complex function like annual energy cost using whole building energy simulation. For example, in the case study of this paper there are two fitness functions defined: one simulates the annual energy cost and the other simulates building daylighting performance. BPOpt is designed in a way that the user can add multiple fitness functions smoothly.

In the fifth step, the results will be generated by feeding variables and fitness functions into the optimization process using Optimo. At this step the BIM model changes according to the identified decision variables and their value ranges in the optimization process and when the transaction of all of the changes in the BIM model is complete, the analytical models are generated or regenerated. The analytical models will be sent to performance simulation engines and the values for the fitness functions will be calculated. After the optimization process is over, a set of optimal solutions will be reported to the designer.

The sixth step is decision making which is to be addressed by designers themselves. The designer evaluates the results and proceeds in two ways: 1) a design option is selected from the optimal solution set provided by this workflow and the design proceeds; or 2) based on the provided results the designer makes changes in the optimization settings and parametric relationships and repeats the same process until desired design is achieved. 


\section{Case Study}

381 In order to evaluate the performance of the proposed workflow in this research, a case study was

382 implemented on the Stanford University Solar Decathlon 2013 house project BIM model

383 (http://solardecathlon.stanford.edu/) with minor modifications (the Revit model of the building was kindly

384 provided to us by the project team). It is a single story residential building with a net floor area of 1018

$385 \mathrm{ft}^{2}$. Figure-4 shows the floor plan, and northwest and southwest 3D views of the house. The building has

386 clearstory windows on the north wall (Figure-4-b) and the curtain panel windows on the south wall

387 (Figure-4-c).
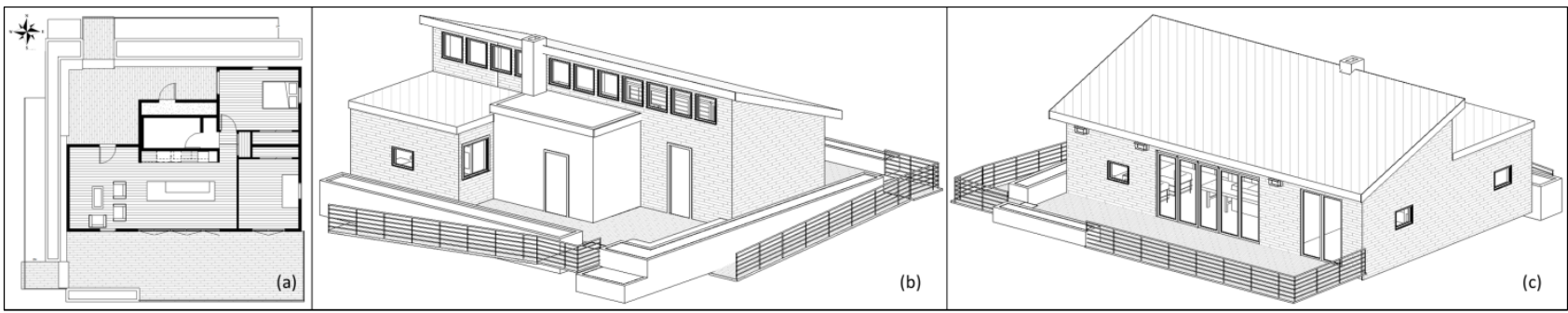

Figure-4. (a) Floor plan (b) Northwest isometric 3D view shows the clearstory windows on the north wall; and (c) Southwest isometric 3D view showing the curtain panel on the south wall. (Source: Stanford University Solar Decathlon 2013 project team.)

\subsection{Objective Functions}

Green building rating systems require building performance efficiency in multiple disciplines. Therefore, the objectives of the optimization routine for this case study are defined from two different disciplines of energy performance and daylighting performance. The objective functions are set to minimize the expected annual energy use while maximizing the regularly occupied area of the residential unit that lies between 300 lux and 3,000 lux for 9 a.m. and 3 p.m. at the equinox to get maximum LEED daylighting credit.

The energy simulation process collects the required information for energy analysis stored in BIM such as geometry information, physical material information, and location data. The daylighting simulation requires building information for geometry, glazing properties, and reflectivity of opaque materials defined in the BIM model. The workflows developed in this project can identify parameters from elements within the BIM model and explore a set of scenarios for energy performance and daylighting adequacy. 


\subsection{Decision Variables}

405 Windows are critical components of building facades (Shen and Tzempelikos, 2010). Glazing form, size and type should be jointly considered in order to effectively control the heat and light transfer through the building. The optimal glazing size and type are unique for each building and should be calculated by taking into account the glazing geometrical and analytical properties for heat gain and loss and lighting requirements. In this study glazing size and analytical properties are selected as parametric variables to study their effect on the building performance. The goal of this study is set to find the optimum windows size and glazing material that result in an energy efficient model with a maximum level of acceptable daylighting.

In this study 7 parameters related to windows and curtain panels are considered as optimization variables.

414 The list of these variables, their acceptable range, and the variable types are given in Table-1. There are two types of variables: 1) glazing geometry variables that relate to the size and shape of the windows; 2 ) performance analytical variables that relate to energy and daylighting performance of glazing. It should be mentioned that BPOpt is not limited to geometry and performance analytical variables and can handle other variables such as those that result in topological changes. The size of casement windows (height and width) on the south, east, west, and north sides of the building are considered as geometry variables. The analytical properties of all windows (casement windows and clearstory windows) and curtain panel windows on the south wall are studied as performance analytical variables.

Table-1. Optimization variables, their acceptable range and types

\begin{tabular}{|l|l|l|l|l|}
\hline \multicolumn{1}{|c|}{ Geometry Variables } & Lower Limits (ft) & Upper Limits (ft) & Variable Type & \multicolumn{1}{|l|}{ Defined Type } \\
\hline Casement Windows Width (South-East-West) & 4 & 8 & Continuous & Double \\
\hline Casement Windows Height (South-East-West) & 1 & 5 & Continuous & Double \\
\hline Casement Windows Height (North) & 1 & 5 & Continuous & Double \\
\hline Casement Windows Width (North) & 1 & 5 & Continuous & Double \\
\hline \multicolumn{1}{|c|}{ Performance Analytical Variables } & Index Min & \multicolumn{1}{|c|}{ Index Max } & Variable Type & Defined Type \\
\hline Casement Windows Material & 0 & 20 & Discrete & List \\
\hline Clearstory Windows Material & 0 & 20 & Discrete & List \\
\hline Curtain Panels Windows Material & 0 & 20 & Discrete & List \\
\hline
\end{tabular}

423 To enable the parametric change of the glazing properties, both for energy simulation and daylighting 424 analysis, 21 glazing types are created for this case study (Table-2). The specific glazing types available to this research are limited to those available in Revit. The analytical properties for glazing in Revit are not automatically set when the glazing type is selected and the user needs to define them for performance analysis. The glazing thermal properties can be modified in the type properties options and the glazing properties for daylighting analysis can be set in the glass pane material's Appearance properties. 
Each glazing type is then assigned with an index (Table-2). The glazing indices are used in the optimization process as performance analytical parameters, which are discrete variables. In the BPOpt workflow, the corresponding glazing types to the indices are selected to be applied to the family instances in the BIM model to create the energy and daylighting analytical models for performance simulation.

Table-2. Available glazing types for this project and their analytical properties

\begin{tabular}{|c|c|c|c|c|}
\hline $\begin{array}{l}\text { Index } \\
\text { Number }\end{array}$ & Analytical Construction & $\begin{array}{l}\text { Visual Lighting } \\
\text { Transmittance }\end{array}$ & $\begin{array}{c}\text { Solar Heat Gain } \\
\text { Coefficient }\end{array}$ & $\begin{array}{c}\text { Thermal Resistance- } \\
\mathbf{R}\left(\mathbf{h} . \mathrm{ft}^{2}{ }^{\circ}{ }^{\circ} \mathrm{F}\right) / \mathrm{BTU}\end{array}$ \\
\hline 0 & $1 / 8$ in Pilkington single glazing & 0.9 & 0.86 & 0.8466 \\
\hline 1 & $1 / 4$ in Pilkington single glazing & 0.9 & 0.86 & 0.8473 \\
\hline 2 & $3 / 8$ in Pilkington single glazing & 0.88 & 0.81 & 0.8478 \\
\hline 3 & $1 / 2$ in Pilkington single glazing & 0.88 & 0.81 & 0.9096 \\
\hline 4 & Double glazing - $1 / 4$ in thick-bluegreen/low-E $(e=0.05)$ & 0.45 & 0.27 & 2.8573 \\
\hline 5 & Double glazing $-1 / 4$ in thick - clear/low-E $(e=0.1)$ & 0.45 & 0.39 & 2.8573 \\
\hline 6 & Double glazing - $1 / 4$ in thick - clear/low-E $(e=0.2)$ & 0.45 & 0.45 & 2.8573 \\
\hline 7 & Double glazing - $1 / 4$ in thick - gray/low-E $(e=0.05)$ & 0.35 & 0.24 & 2.8573 \\
\hline 8 & Double glazing - $1 / 4$ in thick - gray/low-E $(e=0.1)$ & 0.37 & 0.34 & 2.8573 \\
\hline 9 & Double glazing - $1 / 4$ in thick - gray/low-E $(e=0.2)$ & 0.37 & 0.39 & 2.8573 \\
\hline 10 & Double glazing - $1 / 4$ in thick - green/low-E $(e=0.05)$ & 0.6 & 0.31 & 2.8573 \\
\hline 11 & Double glazing - $1 / 4$ in thick - green/low-E $(e=0.1)$ & 0.61 & 0.36 & 2.8573 \\
\hline 12 & Double glazing - $1 / 4$ in thick - green/low-E $(e=0.2)$ & 0.61 & 0.41 & 2.8573 \\
\hline 13 & Double glazing - $1 / 4$ in thick - low-E/clear $(e=0.05)$ & 0.7 & 0.3 & 2.8573 \\
\hline 14 & Double glazing $-1 / 8$ in thick - clear/low-E $(e=0.1)$ & 0.57 & 0.48 & 2.8573 \\
\hline 15 & Double glazing $-1 / 8$ in thick - clear/low-E $(e=0.2)$ & 0.58 & 0.57 & 2.8573 \\
\hline 16 & Double glazing $-1 / 8$ in thick - low-E/clear $(e=0.05)$ & 0.72 & 0.41 & 2.8573 \\
\hline 17 & Single glazing $\mathrm{SC}=0.2$ & 0.08 & 0.19 & 0.8473 \\
\hline 18 & Single glazing $\mathrm{SC}=0.4$ & 0.3 & 0.39 & 0.8473 \\
\hline 19 & Single glazing $\mathrm{SC}=0.6$ & 0.76 & 0.6 & 1.1803 \\
\hline 20 & Single glazing $\mathrm{SC}=0.8$ & 0.88 & 0.81 & 1.1803 \\
\hline
\end{tabular}

\subsection{Optimization Algorithm Encoding and Process}

435 The availability of the visual programming environment allows the design space to be quickly, 436 interactively, and accurately specified. Figure-5 shows the BPOpt workflow graph in Dynamo for this 437 case study. This workflow uses Optimo nodes (Initial Solution List, Assign Fitness Function Results, 438 Generation Algorithm, and Nondominated Sorting) and custom nodes, which are the package of multiple 439 nodes, (NSGA Function BPOpt, Loop Completion Check, Energy Analysis Fitness Function, and 440 Daylighting Analysis Fitness Function) for the optimization process. Daylighting and energy analysis 441 fitness functions are packages of multiple nodes that implement the parametric performance analysis 
through BIM for the optimization process. The generation loop runs the generation and sorting processes in a loop till the run iteration counter reaches the limit that the designer defines. The last section of the Dynamo code writes all of the decision variables in the whole optimization process and their corresponding performance analysis results to a CSV file. It should be noted that the BPOpt workflow is not limited to using of daylighting and energy simulation fitness functions that are developed for this research. The fitness functions and their related decision variables ranges and types can be easily modified by users to apply the BPOpt framework to other performance optimization problems. For instance, Vermeulen (2015) used the BPOpt framework to optimize building structural performance and Hudson and Vannini (2015) used BPOpt to optimize form by its acoustic performance.

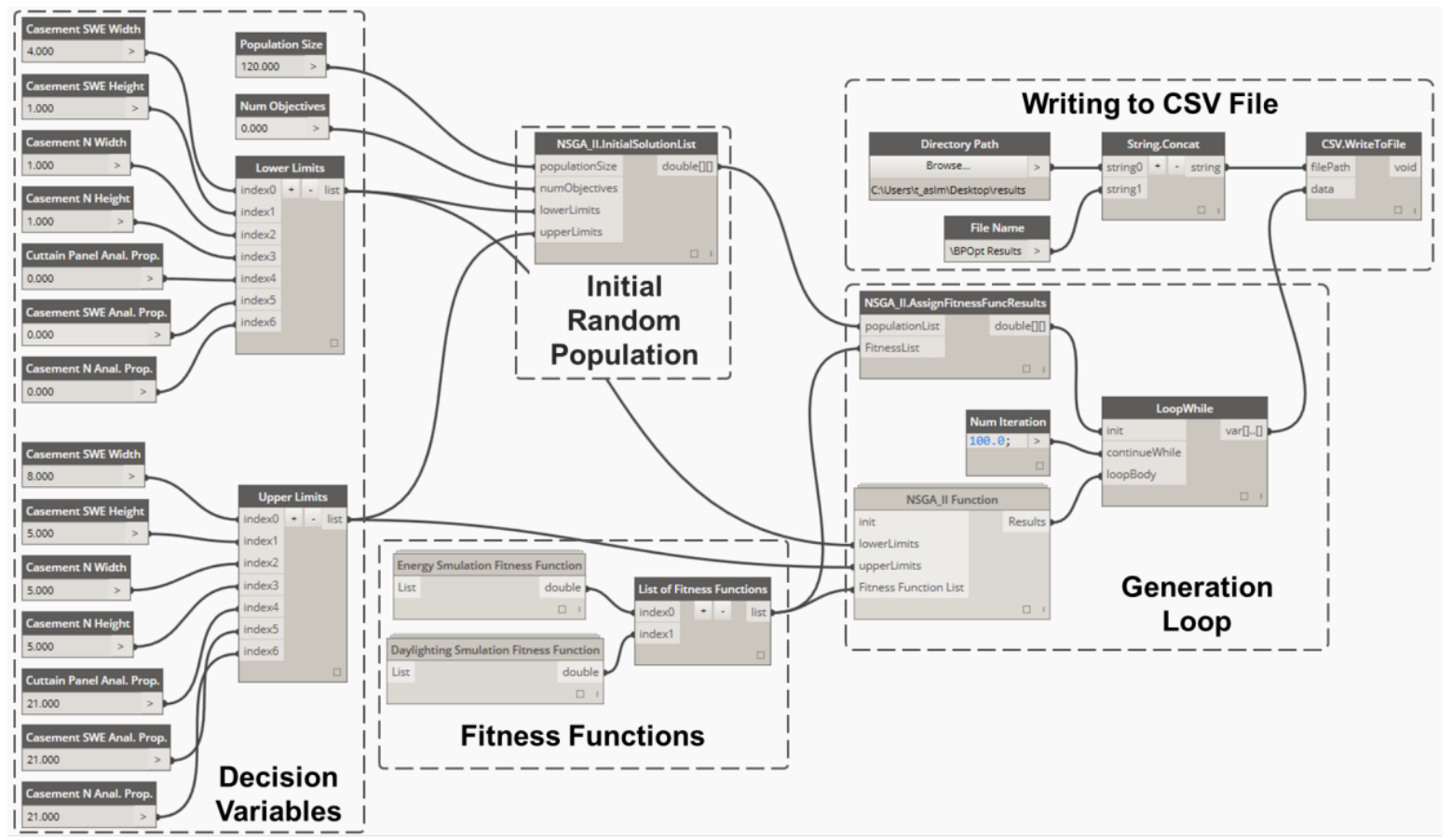

Figure-5. BPOpt workflow graph. The user inputs (population size, number of objectives and variable domains) are inserted on the left side of the graph. The InitialPopulationList node generates initial population list. The inserted fitness functions evaluate fitness values for the initial population list and the results are assigned to the population in the AssignFitnessFunctionResults node. The LoopWhile node iterates the NSGA-IIFunctionBPOpt node to generate

offspring populations and the best nondominated solutions. At the end the results are exported to a CSV file for detailed downstream analyses.

Figure-6 shows the detailed description of the NSGA-II algorithm in Optimo designed for this case study. As it is shown in this image, the random population list is generated first and the fitness function are calculated and assigned for the initial population first. Then the results transfer to generation loop to improve the values in each generation. The generation loop ends when the iteration number reaches the limit that user defines. At the end the optimal results are reported. 


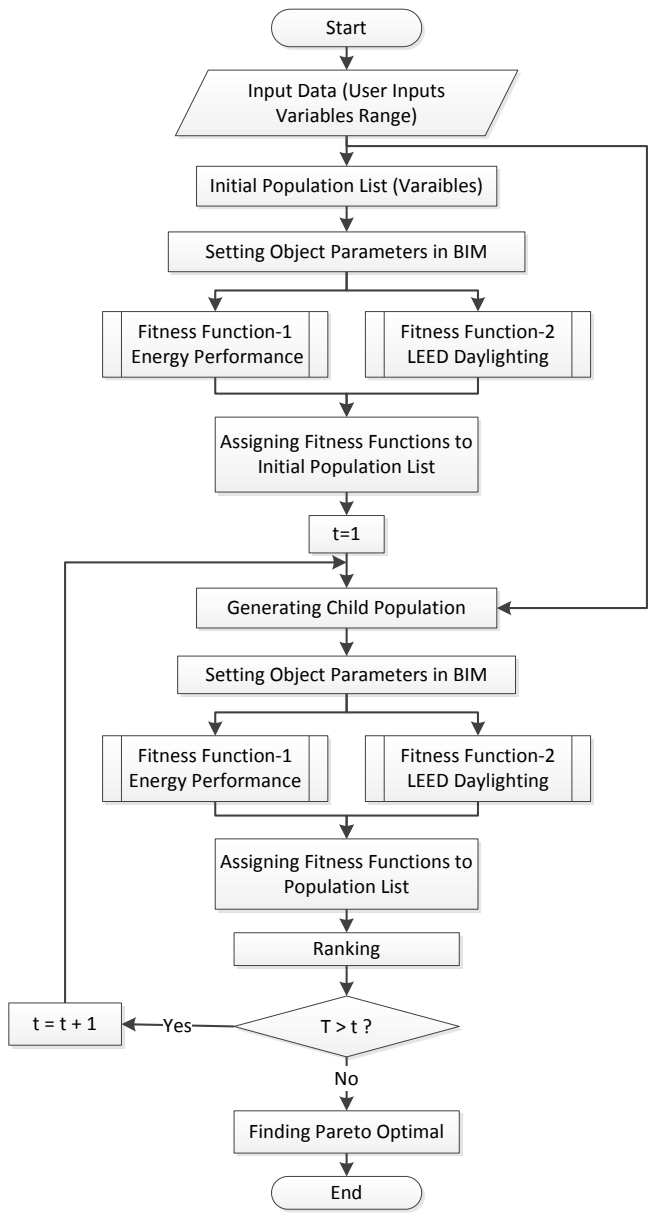

464 Figure-6. The process of using Optimo in BPOpt workflow for the test case experiment to optimize the energy and daylighting performance of the Solar Decathlon Building

466 The NSGA-II algorithm is implemented with the input of a population size of 75 for each generation. The 467 mutation probability is set to 0.01 . The crossover probability is set to 0.9 and both the mutation

468 distribution index and crossover distribution index are set to 20.0. For this experiment the total generation 469 number is set to 15 which results in the total number of 1200 ( 75 from initial solution set and 1125 from 470 generation process) energy simulation runs. Since LEED Version-4 Daylight Option-2 requires

471 demonstrating that the illuminance levels for 9 a.m. and 3 p.m. at the equinox for the floor area regularly 472 occupied floor area, the total number of lighting analyses is 2400 simulation runs. The availability of 473 cloud-based energy and daylighting simulation tools enables the quick evaluation of a large number of 474 design validations. 


\section{4.4. Results}

479 The optimization results are reported in Figure-7. This figure is created in Microsoft Excel using the 480 optimization results that are automatically exported as a CSV file. The fitness functions for the 481 optimization process are defined as follows:

482 - Energy performance factor: Annual energy cost in Dollar

483 - Daylighting performance factor: $100 \%$ subtracting the percentage of the area with illuminance level within the LEED daylighting acceptable range (described in Section 3.3)

486 The optimum solution is at the lower left corner of the graph where the annual energy use at its minimum

487 and the percentage of the area within the acceptable daylighting threshold at its maximum value (the

488 daylighting performance factor is the reciprocal of the area). The results show that the performance

489 optimization process is able to improve the building performance and find the optimal or near optimal

490 solutions from the design space. As one can see, the initial randomly generated solution set is widely

491 distributed (blue diamonds), while the results of later generations are more and more getting clustered

492 towards the lower left corner (the optimum solution). Also it can be observed that every solution in the

493 initial population is dominated by some solutions in the final population, i.e. every solution of the final

494 population is better than each solution of the initial population in both energy and daylighting

495 performance. 


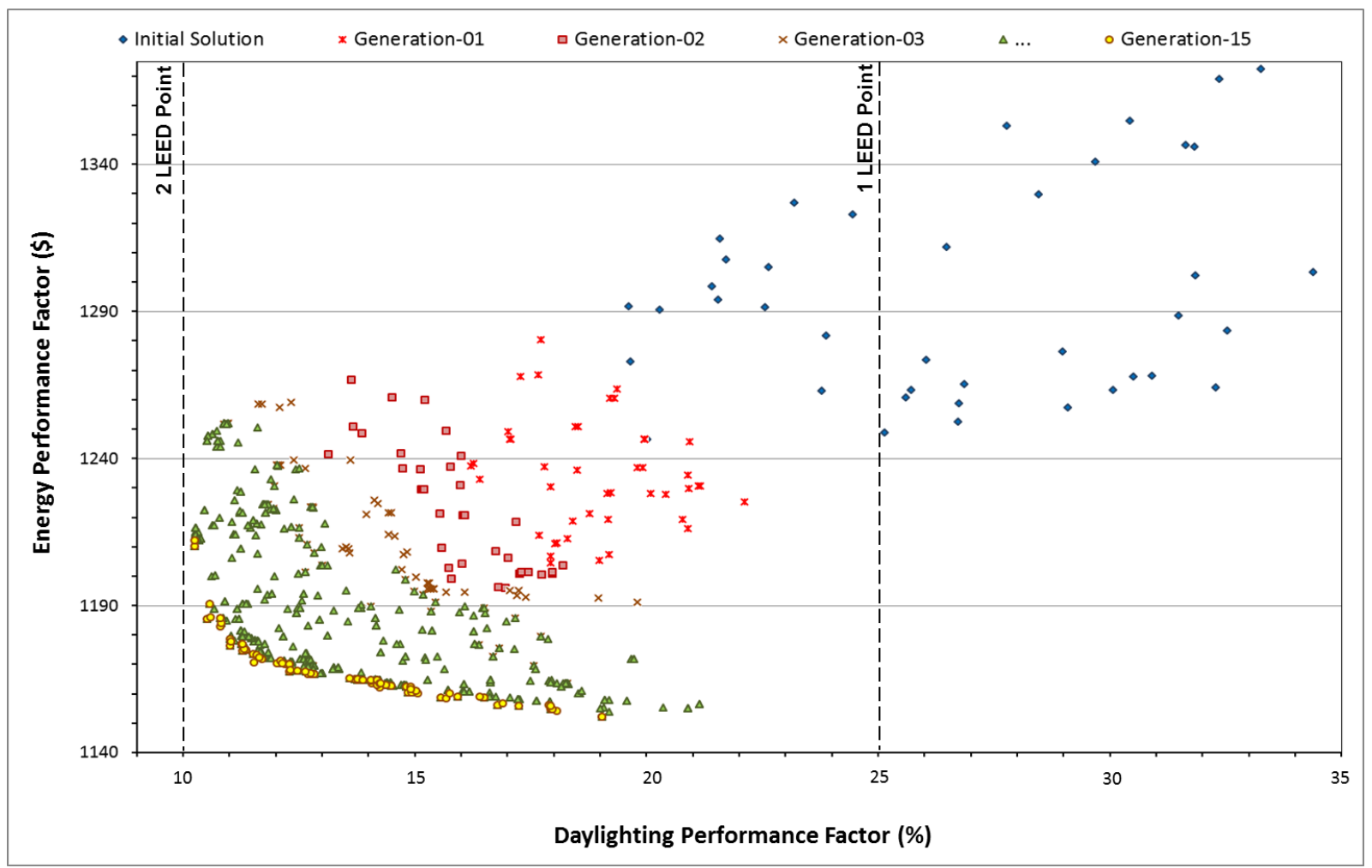

Figure-7. Scatterplot showing the building performance multi-objective optimization results using Optimo (the energy performance factor is the annual energy cost in dollar and the daylighting performance factor is $100 \%$ subtracting the percentage of the area with the illuminance level within the LEED daylighting acceptable range)

Based on LEED Version-4 Daylight Option-2 (described in Section 3.3), and as Figure-7 shows very few alternatives of the initial population set satisfy the LEED requirement to get 1 point for daylighting, while those which satisfy this requirement are not very efficient in energy performance. However, all of the final population set alternatives satisfy the minimum LEED requirement and perform more efficiently in energy use. Moreover, based on the results in the same figure, none of the alternatives could satisfy LEED requirements to get 2 points for daylighting. At this point in case the project needs to get 2 LEED points, the designer can make some changes in the model geometry and windows configuration on the model to try the optimization again as shown in Step 6 of the BPOpt process in Figure-1. Using the same procedure as this experiment shows, the proposed framework can be used to optimize many other performance based problems with different variables and simulations processes.

Figure-8 shows the Pareto Optimal set obtained within the process time and visualized using the exported CSV results. The figure can help designers to understand the relationship between conflicting performance objectives. In this figure three sample alternatives are highlighted and their decision variable values are provided. Alternative-1 has the highest daylighting performance but is not very energy 
efficient. Alternative-2 is moderate in both energy and daylighting performance and alternative- 3 has the best energy performance but the worst in daylighting performance among all Pareto Optimal alternatives. Looking at the Pareto Optimal set, the designer has an option to choose any of the alternatives which satisfy more comprehensive design objectives, including, e.g. functions and aesthetics.

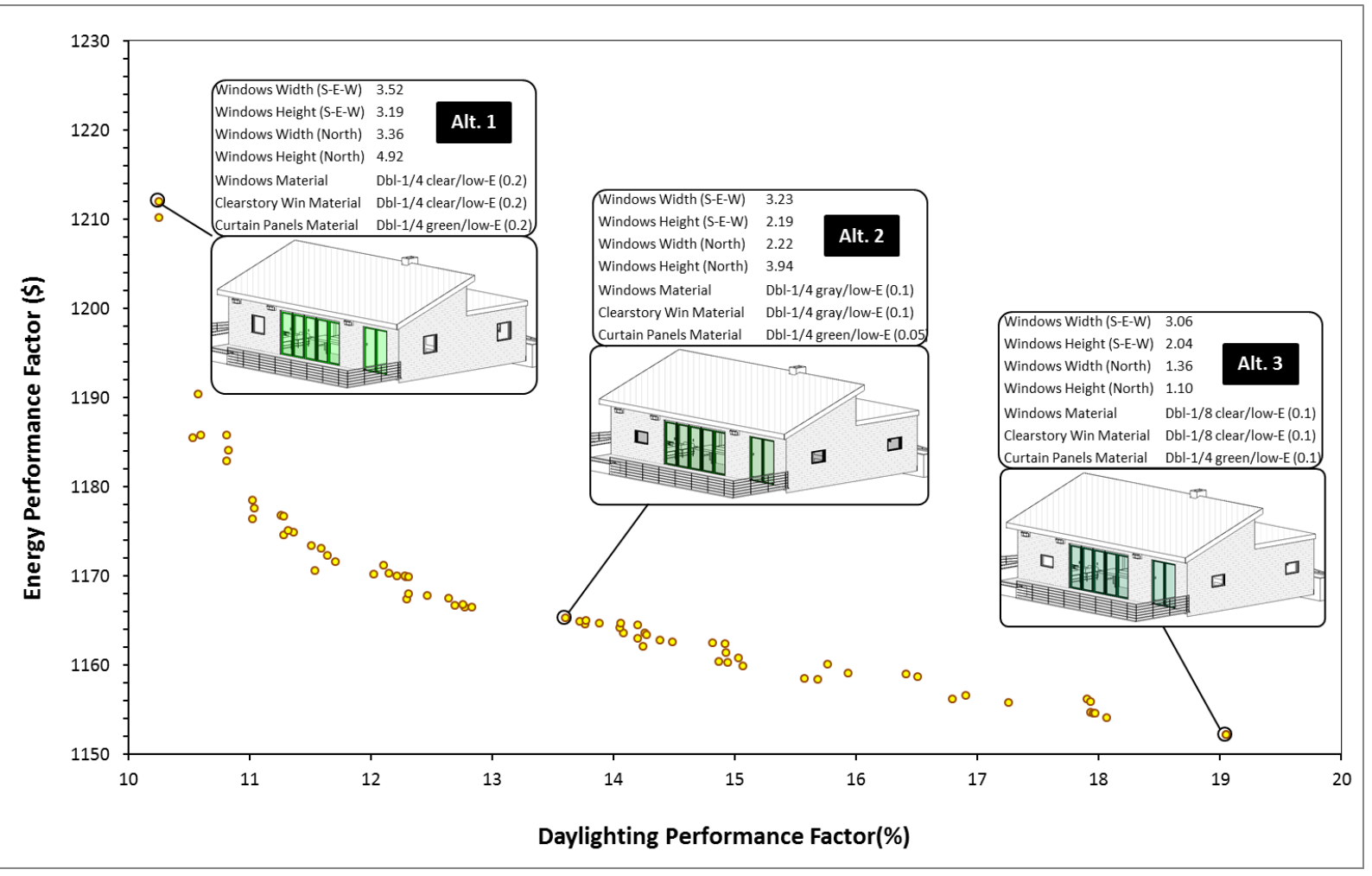

Figure-8. Scatterplot showing the Pareto Optimal set with decision variable values for three alternatives to illustrate the association between the calculated optimal solutions and the variable values.

\section{Conclusions, Discussions, and Future Work}

Building performance optimization based on performance simulation shows a great potential in high performance building design. Incorporating a broader variety of simulations in different domains into the system will lead to a more comprehensive exploration of the solution space and provide better decision support for the designers. Due to the green building design requirements and the advancement of computational methods and tools, there is a clear growth in popularity of building performance optimization methods. The BPOpt workflow is developed as a response to the lack of an integrated framework utilizing a visual programming user interface on the top of widely-used BIM platform to facilitate sustainable and high performance building design. 
One of the significant challenges of the creating BPOpt framework is the interoperability among the various purpose-built software applications, including BIM (Revit), energy simulation (Green Building

532 Studio), daylighting simulation (Autodesk Rendering Service), and optimization (the new Optimo

533 implementing NSGA-II). The project provides a new case study of interoperability that utilizes the

534 Application Programming Interfaces (e.g. Reivt API and GBS-API) in a visual programming

535 environment, which contributes to the existing study of interoperability, in which IFC and gbXML and

536 their related programming interfaces play an important role, as seen in current literature.

537 The BPOpt framework aims to help designers both with and without extensive parametric modeling and

538 computer programming experiences to use a novel BIM-based visual programming interface to perform a

539 broad variety of simulation-based analyses for design optimization. BPOpt integrates the rich information

540 stored in parametric BIM with building performance analysis to make design exploration and

541 performance optimization more accessible in the process of design. By early adoption of Green Building

542 Studio (GBS)-API, BPOpt enables parametric BIM-based building energy simulation, which provides

543 quick energy performance feedback using the power of cloud-based simulation in the process of design.

544 Parametric daylighting simulation is enabled by creating a visual programming package that can simulate

545 multiple runs in parallel on the cloud for the optimization purpose. The parametric energy and daylighting

546 simulation tools are used as a part of the case study in this paper to show the effectiveness of BPOpt

547 framework. However, it should be noted that the functionality of BPOpt framework is not tied to these

548 two performance simulation metrics. The fitness functions and decision variables of BPOpt framework

549 can be modified to optimize the performance of the building design for other metrics and with other tools

550 available to the designer. For instance, Vermeulen (2015) used the BPOpt framework in optimizing

551 structural performance of the building and Hudson and Vannini (2015) implemented it in optimizing

552 acoustic performance of a space.

553 Optimo, which is the core part of BPOpt framework, is developed as a BIM-based visual programming 554 package for multi-objective optimization by implementing the NSGA-II algorithm. Optimo can provide 555 Pareto Optimal sets with diverse solutions of optimal performance that can benefit the decision-making 556 process. Optimo has been published as an open-source package available to the public. The package has 557 been downloaded more than 500 times as of May 2015 by users and received good feedback. As an 558 example, Vannini and Hudson (2015) used Optimo to optimize the form of a space using its acoustic 559 performance and won the first place in AEC Hackathon (Acoustamo, 2014). Their feedback is "Optimo 560 works really well, it is fast and it finds the minimum quickly! In my opinion it would have been easier if 561 the process of modeling was more concise." Some universities such as Georgia Institute of Technology 562 and Stanford University have started teaching Optimo in their graduate level classes and implementing it 
563 in their research as well. Moreover, Optimo has been tried on real design projects in industry by Arup ${ }^{\circledR}$. A

564 more detailed report on these applications will be available in the near future as use cases are collected

565 and analyzed.

566 The use of the BPOpt framework in the present case study has demonstrated the process of using visual 567 programming and parametric BIM-based design space exploration to find optimal solutions. However, 568 due to that Autodesk daylighting simulation service is limited to 4 simultaneous runs for our education 569 account, the total optimization process took more than what was expected. The total simulation time for 570 each generation was 3.5 hours and the whole optimization process took about 56 hours. About one hour 571 of the 56 hours was spent on the parametric changes, model regeneration to export energy and daylighting

572 files, and uploading the models to the cloud engine for simulation. The time that spent for energy

573 simulation was about 2 hours and the time that spent on daylighting simulation was about 3.5 hours.

574 However, the energy and daylighting simulations were performed in parallel which means the overall

575 simulation time was about 3.5 hours. The rest and majority of the 56 hours was spent on the cloud run

576 queues due to the limitations for the education account that was used for this study. When more

577 simultaneous runs are allowed (e.g. for professional and subscription use), the total time for optimization

578 can be significantly reduced.

579 The case study shows how the framework can be used to optimize multiple objectives including energy 580 performance and daylighting performance in different disciplines and improve the overall building 581 performance. The optimization results presented as a Pareto Optimal set provides an option for the 582 designer to trade-off among multiple alternatives and choose the most appropriate design. The new 583 framework can easily accommodate other building performance factors with the same mechanism. 584 Through the continued development of similar projects to enable fast BIM-based simulation and 585 representation of solutions and their trade-offs, designers can better understand the dependencies of 586 design options on the decision variables at the early design stage even without substantial expertise in 587 energy modeling and daylighting analysis.

588 The authors are expanding the optimization algorithms included in Optimo and adding new features to 589 Optimo to better serve designer's needs in the process of performance optimization. Visualizing the 590 optimization results within the same BIM platform will be added to the workflow to help designers 591 navigate through the results quickly and make design decisions in a single design platform that is easy to 592 use. 


\section{Acknowledgements}

We are grateful to the Stanford Solar Decathlon 2013 project team, their Construction Manager Rob Best, and Project Manager Derek Ouyang for providing us with the BIM model of the case study of this project.

[Other acknowledgements are temporarily omitted for blind review]

\section{References}

1. Acoustamo, 2014. Congratulations to our AU 2014 Dynamo Hackathon winner: “Acoustamo: Designed by Sound" | Dynamo BIM.

2. Ahn, K.U., Kim, Y.J., Park, C.S., Kim, I., Lee, K., 2014. BIM interface for full vs. semi-automated building energy simulation. Energy and Buildings 68, 671-678.

3. Aly, M., Nassar, K., 2013. Integrating Performance and Parametric Design Tools for Urban Daylight Enahancement, in: Proceedings of BS2013. Presented at the 13th Conference of International Building Performance Simulation Association, Chambéry, France, pp. 3027-3034.

4. Attia, S., Gratia, E., De Herde, A., Hensen, J.L.M., 2012. Simulation-based decision support tool for early stages of zero-energy building design. Energy and Buildings 49, 2-15.

5. Augenbroe, G., 2002. Trends in building simulation. Building and Environment 37, 891-902.

6. Azhar, S., Brown, J., Farooqui, R., 2009. BIM-based sustainability analysis: An evaluation of building performance analysis software, in: Proceedings of the 45th ASC Annual Conference. pp. 14.

7. Azhar, S., Carlton, W., Olsen, D., Ahmad, I., 2011. Building information modeling for sustainable design and LEED ${ }^{\circledR}$ rating analysis. Automation in Construction 20, 217-224.

8. Bazjanac, V., 2008. IFC BIM-based methodology for semi-automated building energy performance simulation, in: Improving the Management of Construction Projects through IT Adoption. Presented at the CIB W78, Universidad de Talca, pp. 292-299.

9. Bazjanac, V., Crawley, D.B., 1999. Industry foundation classes and interoperable commercial software in support of design of energy-efficient buildings, in: Proceedings of Building Simulation'99. pp. 661-667.

10. Bechthold, M., King, J., Kane, A., Niemasz, J., Reinhart, C.F., 2011. Integrated environmental design and robotic fabrication workflow for ceramic shading systems, in: International Symposium on Algorithms and Computation (ISAAC 2010) in Jeju, South Korea.

11. Boeykens, S., Neuckermans, H., 2009. Visual Programming in Architecture: Should Architects Be Trained As Programmers? Proceedings of CAAD-Futures 2009. 
12. Coley, D.A., Schukat, S., 2002. Low-energy design: combining computer-based optimisation and human judgement. Building and Environment 37, 1241-1247.

13. Cormier, A., Robert, S., Roger, P., Stephan, L., Wurtz, E., 2011. Towards a BIM-based service oriented platform: application to building energy performance simulation. Proceedings of Building Simulation 2011. 2309-2316.

14. Deb, K., Pratap, A., Agarwal, S., Meyarivan, T., 2002. A fast and elitist multiobjective genetic algorithm: NSGA-II. IEEE Transactions on Evolutionary Computation 6, 182-197. doi:10.1109/4235.996017

15. De Boeck, L., Audenaert, A., De Mesmaeker, L., 2013. Improving the energy performance of residential buildings: a literature review. HUBrussel Research Paper 2013/13.

16. Durillo, J.J., Nebro, A.J., 2011. jMetal: A Java framework for multi-objective optimization. Advances in Engineering Software 42, 760-771. doi:10.1016/j.advengsoft.2011.05.014

17. Dynamo BIM [WWW Document], 2015. URL http://dynamobim.org/ (accessed 12.30.14).

18. Evins, R., 2013. A review of computational optimisation methods applied to sustainable building design. Renewable and Sustainable Energy Reviews 22, 230-245.

19. Fischer, M., 2006. Formalizing construction knowledge for concurrent performance-based design, in: Intelligent Computing in Engineering and Architecture. Springer, pp. 186-205.

20. Flager, F., Basbagill, J., Lepech, M., Fischer, M., 2012. Multi-objective building envelope optimization for life-cycle cost and global warming potential, in: Proceedings of ECPPM. pp. 193200.

21. Fonseca, C.M., Fleming, P.J., 1993. Genetic Algorithms for Multiobjective Optimization: Formulation, Discussion and Generalization.

22. Garg, V., Chandrasen, K., Tetali, S., Mathur, J., 2010. EnergyPlus Simulation Speedup Using Data Parallelization Concept, in: AMSE 2010 4th International Conference on Energy Sustainability. Presented at the AMSE 2010 4th International Conference on Energy Sustainability, pp. 1-6.

23. gbXML, 2014. Open Green Building XML Schema: a Building Information Modeling Solution for Our Green World [WWW Document]. URL http://www.gbxml.org/index.php (accessed 1.3.13).

24. gnu.org [WWW Document], 2015. URL http://www.gnu.org/licenses/ (accessed 12.31.14).

25. Gossard, D., Lartigue, B., Thellier, F., 2013. Multi-objective optimization of a building envelope for thermal performance using genetic algorithms and artificial neural network. Energy and Buildings 67, 253-260.

26. Hoes, P., Trcka, M., Hensen, J., Bonnema, B., 2011. Optimizing building designs using a robustness indicator with respect to user behavior, in: Building Simulation Proceedings of the 12th Conference of the IBPSA. pp. 1710-1717. 
27. Jakubiec, J.A., Reinhart, C.F., 2011. DIVA 2.0: integrating daylight and thermal simulations using Rhinoceros 3D, Daysim and Energyplus. Proceedings of Building Simulation 2011 2202-2209.

28. Kim, J.B., Jeong, W., Clayton, M.J., Haberl, J.S., Yan, W., 2015. Developing a physical BIM library for building thermal energy simulation. Automation in Construction 50, 16-28.

29. Konak, A., Coit, D.W., Smith, A.E., 2006. Multi-objective optimization using genetic algorithms: A tutorial. Reliability Engineering \& System Safety 91, 992-1007.

30. Kumar, S., 2008. Interoperability between building information models (BIM) and energy analysis programs. ProQuest.

31. Lagios, K., Niemasz, J., Reinhart, C.F., 2010. Animated building performance simulation (abps)linking rhinoceros/grasshopper with radiance/daysim. Proceedings of SimBuild.

32. Lin, S.-H.E., 2014. Designing-in performance: Energy simulation feedback for early stage design decision making. University of Southern California.

33. Lin, S.-H.E., Gerber, D.J., 2014a. Designing-in performance: A framework for evolutionary energy performance feedback in early stage design. Automation in Construction 38, 59-73.

34. Lin, S.-H.E., Gerber, D.J., 2014b. Evolutionary energy performance feedback for design: Multidisciplinary design optimization and performance boundaries for design decision support. Energy and Buildings 84, 426-441.

35. Machairas, V., Tsangrassoulis, A., Axarli, K., 2014. Algorithms for optimization of building design: A review. Renewable and Sustainable Energy Reviews 31, 101-112.

36. Maile, T., Fischer, M., Bazjanac, V., 2007. Building energy performance simulation tools-a life-cycle and interoperable perspective. Center for Integrated Facility Engineering (CIFE) Working Paper 107.

37. Malkawi, A.M., 2005. Performance simulation: research and tools. Performative Architecture: Beyond Instrumentality Eds B Kolarevic, AM Malkawi (Spon Press, London) pp 85-96.

38. Malkawi, A.M., 2004. Developments in environmental performance simulation. Automation in Construction 13, 437-445.

39. McNeel, R., 2015. Rhinoceros. NURBS modleing for Windows: http://www. rhino3d. com/jewelry. htm.

40. Myers, B.A., 1990. Taxonomies of visual programming and program visualization. Journal of Visual Languages \& Computing 1, 97-123.

41. Nguyen, A., Reiter, S., Rigo, P., 2014. A review on simulation-based optimization methods applied to building performance analysis. Applied Energy 113, 1043-1058.

42. Niemasz, J., Sargent, J., Reinhart, C.F., 2011. Solar Zoning and Energy in Detached Residential Dwellings, in: Proceedings of the 2011 Symposium on Simulation for Architecture and Urban 
Design, SimAUD '11. Society for Computer Simulation International, San Diego, CA, USA, pp. 3745.

43. Ong, Y.S., Nair, P.B., Keane, A.J., 2003. Evolutionary optimization of computationally expensive problems via surrogate modeling. AIAA journal 41, 687-696.

44. Paoletti, G., Avesani, S., Exner, D., Lollini, R., 2011. Designing low energy buildings: application of a parametric tool and case studies. Presented at the 27th International Conference on Passive and Low Energy Architecture, Louvain La Neuve, Belgium.

45. Phoenix Integration, 2013. Design Exploration and Optimization solutions: Tools for Exploring, Analyzing, and Optimizing Engineering Designs. [WWW Document]. URL http://www.phoenixint.com/software/phx-modelcenter.php

46. Rahmani Asl, M., Bergin, M., Menter, A., Yan, W., 2014. BIM-based Parametric Building Energy Performance Multi-Objective Optimization, in: The 32nd International Conference on Education and Research in Computer Aided Architectural Design in Europe. Presented at the Fusion, Newcastle upon Tyne, UK: Northumbria University, pp. 455-464.

47. Rahmani Asl, M., Stoupine, A., Zarrinmehr, S., Yan, W., 2015. Optimo [WWW Document]. GitHub. URL https://github.com/BPOpt/Optimo (accessed 1.21.15).

48. Rahmani Asl, M., Zarrinmehr, S., Yan, W., 2013. Towards BIM-based Parametric Building Energy Performance Optimization, in: Proceedings of the 33rd Annual Conference of the Association for Computer Aided Design in Architecture (ACADIA). 101-108.

49. Roudsari, M.S., Pak, M., 2013. LADYBUG: A PARAMETRIC ENVIRONMENTAL PLUGIN FOR GRASSHOPPER TO HELP DESIGNERS CREATE AN ENVIRONMENTALLY-CONSCIOUS DESIGN.

50. Roudsari, M.S., Pak, M., Smith, A., 2013. Ladybug: A Parametric Environmental Plugin for Grasshopper to Help Designers Create an Environmentally-Conscious Design, in: Proceedings of bs2013: 13th Conference of International Building Performance Association, Chambery, France, August. pp. 26-28.

51. Sargent, J., Niemasz, J., Reinhart, C.F., 2011. SHADERADE: Combining Rhinoceros and EnergyPlus for the design of static exterior shading devices, in: Building Simulation. pp. 1-9.

52. Shen, H., Tzempelikos, A., 2010. A parametric analysis for the impact of facade design options on the daylighting performance of office spaces.

53. Shi, X., Yang, W., 2013. Performance-driven architectural design and optimization technique from a perspective of architects. Automation in Construction 32, 125-135.

54. Stevanović, S., 2013. Optimization of passive solar design strategies: A review. Renewable and Sustainable Energy Reviews 25, 177-196. 
55. Sustainable Buildings and Climate Initiative, 2009. Common Carbon Metric for Measuring Energy Use \& Reporting Greenhouse Gas Emissions from Building Operations. United Nations Environment Programme (UNEP).

56. US Dept. of Energy, 2012. Building Energy Data Book.

57. Vannini, A., 2015. Architecture and Computation [WWW Document]. andreaarch | Architecture and Computation. URL https://andreaarch.wordpress.com/ (accessed 5.22.15).

58. Vermeulen, D., 2015. Dynam(o)ite your Design for Engineers - part 5. Revit beyond BIM.

59. Wang, W., Zmeureanu, R., Rivard, H., 2005. Applying multi-objective genetic algorithms in green building design optimization. Building and Environment 40, 1512-1525.

60. Welle, B., 2012. Parametric Attribution and Decomposition Methodologies for Product Model-Based Thermal Simulation using Multidisciplinary Design Optimization (MDO) Environments. Stanford University.

61. Welle, B., Haymaker, J., Rogers, Z., 2011. ThermalOpt: A methodology for automated BIM-based multidisciplinary thermal simulation for use in optimization environments, in: Building Simulation. pp. 293-313.

62. Welle, B., Rogers, Z., Fischer, M., 2012. BIM-Centric Daylight Profiler for Simulation (BDP4SIM): A methodology for automated product model decomposition and recomposition for climate-based daylighting simulation. Building and Environment 58, 114-134. doi:10.1016/j.buildenv.2012.06.021

63. Wetter, M., Polak, E., 2004. A convergent optimization method using pattern search algorithms with adaptive precision simulation. Building Services Engineering Research and Technology 25, 327-338.

64. Wetter, M., Wright, J., 2004. A comparison of deterministic and probabilistic optimization algorithms for nonsmooth simulation-based optimization. Building and Environment 39, 989-999.

65. Wright, J.A., Loosemore, H.A., Farmani, R., 2002. Optimization of building thermal design and control by multi-criterion genetic algorithm. Energy and Buildings 34, 959-972.

66. Yan, W., Clayton, M., Haberl, J., Jeong, W., Kim, J.B., Kota, S., Alcocer, J.L.B., Dixit, M., 2013. Interfacing BIM with Building Thermal and Daylighting Modeling, in: 13th International Conference of IBPSA. Chambery, France.

67. Zhang, Y., Korolija, I., 2010. Performing complex parametric simulations with jEPlus, in: Proceedings of the 9th SET Conference, Shanghai, China. 


\section{Building Performance Optimization (BPOpt) Workflow}

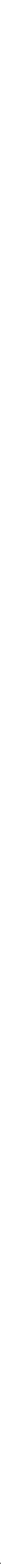

